However, an experienced UK role player has argued strongly in favour of method acting in order to give convincing performances. She considers these simulations appropriate even for amateur actors so long as they have a sense of humour and the capacity to 'switch off' afterwards. ${ }^{4}$

In keeping with American professional role players, ${ }^{4}$ ours liked their work and felt it had allowed them to develop greater empathy towards people with mental illness. They said they had come to appreciate the human exchange that seemed to them central to a psychiatric consultation and felt more able to deal with psychiatric problems experienced by friends and family. They felt that psychiatric role playing can be physically demanding, much of the simulation being non-verbal. They found some very intense scenarios distressing, disturbing and draining, but they did not find the work disturbing overall; they felt they could shrug their roles off afterwards. They regarded psychiatric role playing as interesting and satisfying. Although they reported no continuing stress or adverse consequences from their work, they agreed collectively that only experienced role players should undertake psychiatric roles. So whether a role player is stressed or distressed by simulating may reflect his or her experience. The individual's emotional stability and buoyancy may also be important. Their trainer writes that 'an individual with baggage from personal experience may need more support when de-roling and, in our experience, may be unsuitable'.5

Ours is the first study of the experience of UK role players. Its main limitation is that it draws on a small number of role players from only one programme and may therefore not be representative of the UK as a whole. Also, OSCEs have now been replaced by Clinical Assessment of Skills and Competencies (CASCs) in the Royal College of Psychiatrists examinations. Nonetheless, there are sufficient similarities between OSCEs and CASCs to render our study still relevant.

Declaration of interest

S.M. has 6 years' experience delivering mock OSCEs and CASCs, working with role players from RolePlay North.

1 Bokken L, Van Dalen J, Jan-Joost R. Performance-related stress symptoms in simulated patients. Med Educ 2004; 38: 1089-94

2 McNaughton N, Tiberius R, Hodges B. Effects of portraying psychologically and emotionally complex standardized patient roles. Teach Learn Med 1999; 11: 135-41.

3 Naftulin DH, Andrew BJ. The effects of patient simulations on actors. J Med Educ 1975; 50: 87-9.

4 Davies M. The way ahead: teaching with simulated patients. Med Teach 1989; 11: 315-20.

5 Spence J, Dales J. Meeting the needs of simulated patients and caring for the person behind them. Med Educ 2006; 40: 3-5.

Sally Mitchison is Consultant Psychiatrist in Psychotherapy, Cherry Knowle Hospital, Ryhope, Sunderland, email: sally.mitchison@ntw.nhs.uk, Priya Khanna is specialty registrar (ST6) in general adult psychiatry, Queen's Medical Centre, Nottinghamshire Healthcare NHS Trust, Nottingham

doi: $10.1192 / p b .34 .12 .542$

\section{Staff attitudes to recovery}

We read the paper by Gudjonsson et al ${ }^{1}$ with interest. We wish to highlight the findings of our study in Ireland, which examined the knowledge and attitudes of mental health professionals ( $n=153$, nurses, doctors, social workers, occupational therapists and psychologists) to the concept of recovery in mental health across both in-patient and community settings. ${ }^{2}$ We used the Recovery Knowledge Inventory $(\mathrm{RKI}){ }^{3}$ an instrument developed in the USA but which we found useful for an Irish population, and which has also been found to be of use in European and Australian populations. ${ }^{4}$ The RKI was developed to gauge recoveryoriented practices among providers. It assesses four domains of understanding: roles and responsibilities in recovery; nonlinearity of the recovery process; roles of self-definition and peers in recovery; and expectations regarding recovery. It comprises 20 items, each of which is rated on a 5-point Likert scale.

Our study findings concurred with Gudjonsson et al in finding that respondents viewed recovery positively as a philosophy of care for delivering mental health services. Participants in our study indicated their positive approach to recovery and expressed a need for more training, acknowledging the need for interprofessional learning as a team and the need for a multidisciplinary team approach to care. Respondents were less comfortable with encouraging healthy risk-taking.

However, whereas Gudjonsson et al report that experience of working in forensic services was not significant to total scores, in our study less experienced staff scored higher in having more positive attitudes and knowledge regarding recovery. Also of interest was that females and non-nursing professionals scored higher than nursing professionals in our study. We found no significant difference between in-patient or community-based staff; $22 \%$ of our staff had received training in recovery, compared with $37 \%$ in Gudjonsson et al's study. We did not compare results of those with training and those without, sharing the concern that those who had received training may have been positive about recovery before training.

Both studies discuss decision-making and its challenges around choice and control, and both are in strong agreement regarding hope and optimism being central to the process. Finally, both studies support the idea that irrespective of the specialty (or indeed country), the delivery of a recovery approach to care can be implemented, and knowledge and attitudes of mental health professionals are key in this process.

We look forward to the findings of the prospective study on the recovery approach currently under investigation by Gudjonsson and colleagues, and further discussion on this important topic.

1 Gudjonsson GH, Webster G, Green T. The recovery approach to care in psychiatric services: staff attitudes before and after training. Psychiatrist 2010; 34: 326-9.

2 Cleary A, Dowling M. Knowledge and attitudes of mental health professionals to the concept of recovery in mental health: a questionnaire survey. J Psychiatr Mental Health Nursing 2009; 16: 529-45.

3 Bedregal LE, O'Connell M, Davidson L. The recovery knowledge inventory: assessment of mental health staff knowledge and attitudes about recovery. Psychiatr Rehab J 2006; 30: 96-103.

4 Meehan $\mathrm{T}$, Glover $\mathrm{H}$. Using the recovery knowledge inventory (RKI) to assess the effectiveness of a consumer-led recovery training program for service providers. Psychiatr Rehab J 2009; 32: 223-6.

Anne Cleary is Advanced Nurse Practitioner (Candidate), Recovery and Rehabilitation in Psychosis, Galway Mental Health Services, Ballinasloe, Co Galway, Ireland, email: anneg.cleary@hse.ie; Maura Dowling is Lecturer in Nursing, Postgraduate Coordinator, School of Nursing and Midwifery, National University of Ireland, Galway

doi: $10.1192 / p b .34 .12 .542 a$ 